\title{
Credit Risk Evaluation of Supply Chain Financing of Small and Medium-Sized Enterprises
}

\author{
Zhao Xueying \\ College of Electronic and Information Engineering \\ Shengyang Aerospace University \\ Shengyang China \\ sudnday@126.com
}

\author{
Lian Fenghui \\ Flight Vehicle Control Deparment \\ Aviation University of Air Force \\ Changchun, China \\ 990378945@qq.com
}

\begin{abstract}
-with the rapid development of market economy in our country, the status of small and medium-sized enterprises in our country national economy is more and more high. But now, there are many restrictive factors hindering the development of small and medium-sized enterprises, including financing which is still one of the prominent problems restricting the development of small and medium-sized enterprises at present stage. In this case, Supply chain financing comes into the line of sight of people as a new financing model, it embarks from the supply chain structure and trading characteristics, with the help of the whole supply chain core enterprise credit strength and the value of the flow of goods, providing comprehensive financial services for single or multiple of small and medium-sized enterprises on the supply chain. It has broken the traditional limitation, from global level of industry supply chain, can effectively alleviate the financing difficulties of small and medium-sized enterprises in our country. So, in order to improve the financing difficulties of small and medium-sized enterprises in our country, it is very necessary to do a systematic study related theory of supply chain financing. To financing credit question, however, is still one of the important factors that must be considered. Based on this, under the guidance of the theory of supply chain management, the article made a systematic research of evaluation credit risk of small and medium-sized enterprise supply chain financing.This article revealing the advantage of supply chain financing from the perspective of credit risk evaluation, finally providing a little thought for easing the financing difficulties of small and medium-sized enterprises in our country.
\end{abstract}

Keywords-small and medium-sized enterprises; supply chain financing; credit risk evaluation

\section{RELATED INTRODUCTION OF SUPPLY CHAIN FINANCING AND CREDIT RISKS}

\section{A. Introduction of supply chain financing}

Supply chain financing refers to a kind of financing model that the bank examines the overall situation of supply chain firstly to grasp the scale and strength of the entire supply chain, especially learning the overall strength of core enterprises, and provides financial solutions for the core enterprises and their upstream and downstream enterprises. Supply chain financing is a system consisted of banks, supply chain node enterprises, third-party logistics companies. The essence of supply chain financing is taking all the companies in the supply chain as risk integration, banks relying on the core enterprises, to reduce lending risks through the control of future enterprises earnings.

\section{B. Introduction of credit risks}

Credit generally refers to the practice for what the individuals or enterprises promised to do, and if he can do it, it is proved that he has the credit. After human society entered the commodity economy, credit has become an important factor in the development of human society. After into the market economy period, credit is very important. In the current credit economy, the narrow credit mainly refers to funds credit, which is mainly because the trust of borrower and considering it will be able to practice repayment behavior, and generate immediate funds lending behavior.

\section{ANALYSIS ON CHINESE SMES FINANCING PROBLEMS}

\section{A. SMEs credit financing difficulties}

Although the indirect financing that mainly consisting of bank loan has become the main channel of SMEs financing, but SMEs credit financing is insufficient seriously and the financing gap is very large. The commercial banks in China prefer to supplying loan to large-scale enterprises from the prospect of benefit and operation risk, ignoring the SMEs that is small scale, does not have abundant capital and lack of effective guarantee pledge.

\section{B. Problems of supply chain financing credit risk}

There are two aspects of SMEs financing credit risks, that is, the defects of SMEs ad bank loan system.

1) The reasons of $S M E S$

a) The credit consciousness of SMEs is indifferent, and their credit status is bad.

The operations of small and medium enterprises that occupy the most of Chinese enterprises are not standardized and their systems are not sound, resulting in 
their lower credit rating. Most of the SMEs have never done credit rating, while enterprises credit is the concentrated expression of overall qualities. As the credit consciousness of SMEs is relatively indifferent, they do not want to be responsible for their own lending situation or repay the loan, even willful default.

b) Financing cost of SMEs is higher, and their risk resistant ability is poor

SMEs have small scale operation management and limited capital, and some of them can only operate single product, so their profit resource is only limited in the sole product. With market competition more and fiercer, once market requirement changes, it will affect the performance of SMEs for sure. SMEs

c) Low profit level and limited profit earning of

Most of the SMEs have limited business capacity and lacks of talents. They will face various problems in the production process inevitably, which increases their financing risks.

d) Serious information asymmetry between the bank and the enterprise, resulting in adverse selection and moral risk.

Imperfect management system of SMEs, irregular management system, and limited information within the interior result in the exterior cannot obtain accurate information. So the bank cannot grasp their authentic communication of capital status, business scale and so on.

2) Reasons of the banks

a) Affected by the traditional concept, they do not have policy-based finance system for SMEs financing.

Just affected by the traditional old concept, bank loan is usually with government ownership property. Because the civil small banks cannot meet the requirements of SMEs currently, SMEs loan is mainly depending on nationalized bank.

b) The loan types provided by the bank are not suitable for SMEs

Under normal circumstances, SMEs loans are generally small. Because SMEs are weaker, if disposable borrowing is too much and cannot pay back before expires, and then they can not only take inefficient use of the funds, but also the risk of principal and interest will increase. The stateowned commercial banks generally provide large loans, thus causing waste. Therefore, when the SMEs need loans from commercial banks, they will be in a dilemma.

3) Other reasons

a) Bad credit cooperation and unsound credit rating system

Because of the information asymmetry between the bank and the enterprise, the cooperation between them is not based on faith, so the bank cannot judge the credit status of SMEs correctly and reasonably. Besides, they all want to get maximum benefits. But the result is that they not only cannot obtain win-win effect, but also get mutual benefits damaged. However, the SMEs that are weaker usually lose more, resulting in financing difficulty.

b) Lack of supporting mechanism to maintain banks credit that the equity of the bank cannot be protected

Currently China has no mechanism for supporting the maintenance of bank debt, that is, after bank lending,
SMEs do not perform due repayment obligations, and the money will be defaulted. And for this condition, the bank basically cannot be protected by law and policy. Therefore, banks are reluctant to lend to SMEs easily, which also hindered the financing of SMEs.

\section{SUPPLY CHAIN FINANCING CREDIT RISKS ASSESSMENT}

\section{A. Supply chain financing credit risk assessment index system construction}

1) Construction principle for credit assessment index system

Enterprises credit assessment can be done after determining assessment index system. To ensure the assessed results objective and fair, a set of scientific and sound credit assessment index system will be needed. Therefore, only guided by correct principles, the established credit assessment index system can meet the expected requirements.

\section{a) Scientificity}

The scientificity of setting index system will influence the assessment quality strongly. After the system established, its scientificity shall be enhanced gradually and improved based on continuous practice to make various indexes form dynamic integration and complete system.

\section{b) Pertinence}

Pertinence means the index systems are different with the enterprises' industries and regions. For the enterprises with different types and different operation characteristics, the assessed index is different. Therefore, partial indexes in the credit assessment index system should be adjusted properly to ensure true and reliable final results.

\section{c) Operability}

Operability means the setting of index system should avoid too complex levels, and the calculated formulas should be scientific and reasonable; the index data for calculation should be easy for collecting; the assessment process should be easy to use and operate, simple and useful. The index in assessment index system should ensure the practicability and reality. The index can be obtained through calculation, and the unavailable indexes cannot be selected.

\section{B. The influence factors analysis of enterprise credit risk under supply chain financing}

The factors are very complex. The paper analyzes from three aspects, see the table.1 the credit risk assessment primary index system under supply chain financing mode.

TABLE I. THE CREDIT RISK ASSESSMENT PRIMARY INDEX SYSTEM UNDER SUPPLY CHAIN FINANCING MODE

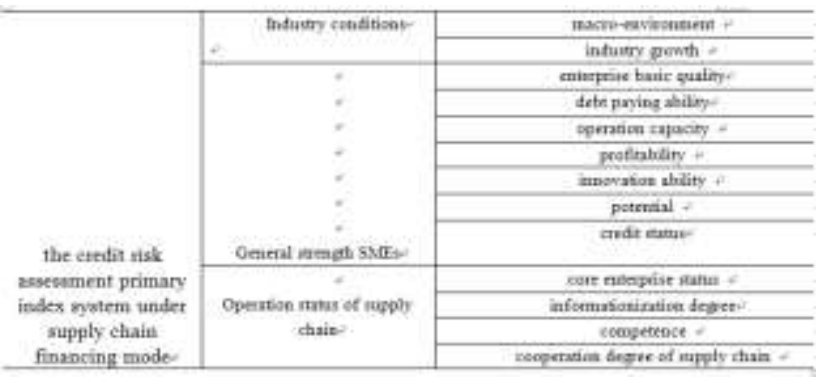




\section{1) Industry status}

Industry status belongs to systematic risk, affected by many comprehensive factors, such as industry growth, macro-economic environment and so on. Industry status analysis for enterprises can help the bank judge the life cycle phase of their belonging industries and their sensibility for economic changes.

2) SMEs comprehensive strength

SMEs comprehensive strength can reflect their operating ability and credit status fully.

3) Operation status of supply chain

The whole business status of supply chain, at which the SMEs locate, will affect their credit assessment directly. Good supply chain operating status will generate less transaction risks, and weaken the comprehensive credit risk of SMEs.

\section{Establish risk assessment index system under supply chain financing mode}

According to the above-mentioned research on supply chain financing credit risks, and complying with its designed principle, the supply chain financing credit risk assessment index system will be established at last.

1) SMEs credit risk assessment index system under supply chain financing mode

According to the above-mentioned analysis, there are totally three levels: that is target level $\mathrm{u}$, first class criterion level Ui and second class criterion level Uij. See Fig.1 supply chain system.

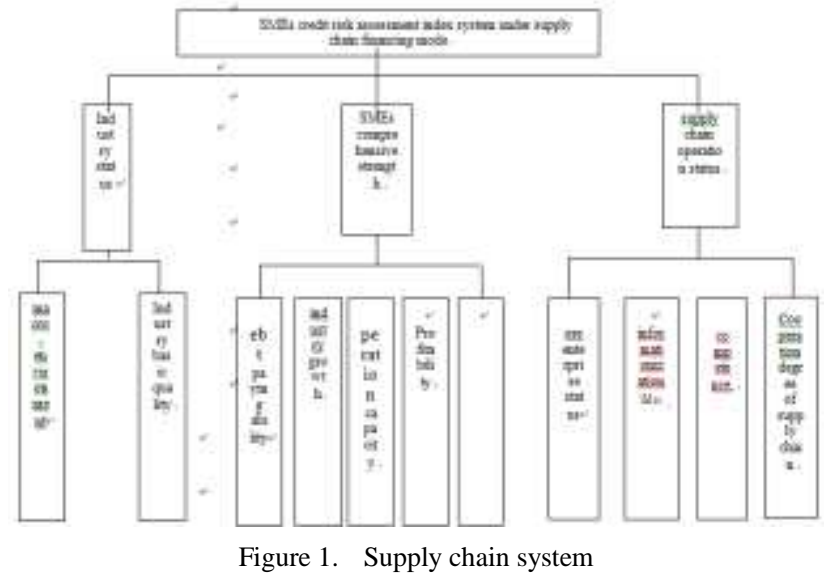

2) supply chain financing mode

To highlight the advantages of supply chain financing mode, supply chain financing mode will be compared and analyzed with non-supply-chain financing mode below. The paper combines the SMEs credit risk contents and characteristics of non-supply-chain financing, and establish Fig.3.2 non-supply-chain system finally by removing the index of supply chain operating status.

3) Basic steps of supply chain financing credit risk comprehensive assessment

The paper refers to analytic hierarchy process to establish credit assessment model

Step 1: propose SMEs credit assessment index system according to SMEs credit assessment characteristics and analytic hierarchy process with the corresponding scales of each level index, to establish judgment matrix.

Step 2: calculate the weight of each level indexes according to judgment matrix;
Step 3: consistency check of judgment matrix;

Step 4: after consistency check of judgment matrix, calculate the synthetic weight of each index in credit assessment;

Step 5: to get the enterprise's final credit score according to their financial statement and other credit assessment, and comparing SMEs credit assessment score standard table;

Step 6: to get the conclusion of enterprise credit assessment according to credit score, credit grade comparison and score instructions.

\section{ESTABLISHMENT OF CREDIT RISK ASSESSMENT MODEL}

The credit risk assessment issues in this paper are multi-attribute decision-making, which should be selecting with complete consideration and depend on multiple principles to reflect its synthetic effects and advantages and disadvantages. Analytic hierarchy process is an effective decision tool with distinct characteristics, such as easy to use and understand, high practicability and so on. These characteristics need to be emphasized to consider by the enterprise for establishing credit risk assessment system.

Analytic hierarchy process (Analytic Hierarchy Process, hereinafter referred to as AHP) was proposed by American operations researcher $T \cdot L \cdot S a t t y$ in 1973 , which is a simple and practical multi-criteria decision method combined with quantitative analysis and qualitative analysis.

There are four steps basically for using analytic hierarchy process to make decision:

\section{A. Establish judgment matrix}

The key step for AHP decision making analysis is to establish judgment matrix. The judgment matrix means for the up-level certain element, the degree of importance of each element as following:

$$
\begin{gathered}
B=\left(\begin{array}{ccc}
b_{11} & \ldots & b_{1 n} \\
\vdots & \ddots & \vdots \\
b_{n 1} & \cdots & b_{n n}
\end{array}\right) \text { Or } \\
B=\left(b_{i j}\right), i, j=1,2, \ldots n
\end{gathered}
$$

Within the range of this level, the elements weight can be obtained through pair comparison. The importance of each element needs to be compared in pair. The paper adopts 1-3 scale method to compare in pair, such as the definitions in table 3.2.

\section{B. Calculate the weight of each element}

Determine corresponding eigenvector according to the established judgment matrix above, and then can get the weight of each SMEs credit assessment element under the same standard.

1) Calculate the product of judgment matrix elements in each line

$$
M_{i}=\prod_{j=1}^{n} b_{i j}(i=1,2, \ldots n)
$$

2) Calculate $n$ power root of line $m$ 


\section{$\overline{W_{i}}=\sqrt[n]{M_{i}}$}

3) Process the vector quantity as normalization processing.

$$
W_{i}=\frac{\overline{W_{i}}}{\sum_{i=1}^{n} \overline{W_{i}}}
$$

\section{4) Check consistency}

Target judgment matrix is able to meet consistency conditions. The elements comparison value of the same judgment matrix should also comply with logic. If not, the judgment matrix will be nonsense, and a new judgment matrix will be needed. In the actual application, people's favor and judgment standard is different, so judgment matrix consistency will have certain shortcomings. Therefore, we use consistency index (Consistency Index, CI) to check judgment matrix consistency. Usually, when the matrix multiplicity $>2$, consistency check will be needed.

$$
C I=\left(\lambda_{\max }-n\right) /(n-1)
$$

$\mathrm{CI}$ is consistency index; $\mathrm{n}$ is the judgment matrix multiplicity; $\lambda \max$ is the eigenvalue of maximum of judgment matrix.

5) Calculate synthetic weight

Following statistics will be obtained through settling the investigation results above.

$$
b_{i j}=\frac{1}{n} \sum_{k=1}^{n}\left(b_{i j}^{\prime}\right)_{k}
$$

$\left(b_{i j}^{\prime}\right)_{k}$

$i$

the $\mathrm{j}$ class degree of importance;

$\mathrm{n}$ - means the effective quantity of questionnaire

After determining $b_{i j}$ at last, calculate the synthetic weight through the weight calculation method above and conduct consistency check.

6) Determine the credit rating

After determining credit synthetic assessment value, use it compare with table 3.4 credit rating assessment table to assess SMEs credit rating and credit status and determine whether to give loan to the SME.

\section{CONCLUSION}

The paper states the connotation and characteristics of supply chain financing mode and analyze the status of SMEs financing, using analytic hierarchy process and combining case analysis to get synthetic assessment for SMEs credit under supply chain financing mode.
Supply chain financing is a kind of new financing mode. The current research for is not mature enough, so there are still many problems needing further research.

\section{REFERENCE}

[1] Liang Yaqiao. Supply chain financing risk management[J], Market modernization, 2010

[2] Wang Shuchang, Li Junfeng. New ways of SMEs financingsupply chain financing $[\mathrm{J}]$, Operators, 2009

[3] Zhang Yifei, Wang Zongmin. China business circle (next half month) [J], Zhengzhou University commercial college, 2010

[4] Deng Ru, Yang Jiansong. Supply chain financing: New ways of SMEs financing [J].Finance and accounting communication, 2009, (23).

[5] Li Qin, Han Kai. The status and problems of supply chain financing: 93 enterprises samples [J]. Reform, 2009,(06).

[6] Ma Zhili, Cao Fangxiang. On the causes and countermeasures of SMEs[J].Economic research guide, 2009(15):67-68

[7] Liu Yuanhong, Luo Ming. Establishment and research of supply chain assessment system, Commercial research 2007, (5) :332

[8] Sun Yunwu. Statistics-Data collection, settlement and analysis [M], Shanghai: Shanghai University of Finance and Economics, 2009, 199-205

[9] Hunter, William C, Smith, Stephen D. Risk Management in the Global Economy ; A Review Essay[J]. Journal of Banking and Finance, 2002, (5). 